Stéphane Deneu MD, Jose Coddens MD, Thierry Deloof MD

\section{Catheter entrapment by atrial suture during minimally invasive port- access cardiac surgery}

Purpose: The port-access approach allows surgeons to perform heart operations through small intercostal openings, or "ports". This technique requires new skills for anesthesiologists. A pulmonary artery venting (PAV) catheter and, in some cases, a coronary sinus catheter (for administration of retrograde cardioplegia) are positioned with the aid of fluoroscopy and transesophageal echography (TEE). Both catheters have a wider diameter than the more commonly used conventional PA catheter and present distinctive features. We report a case in which a pulmonary artery venting catheter was entrapped by a suture during a port-access procedure.

Clinical Features: A 35-yr-old man with severe mitral valve insufficiency was scheduled for valve repair. After a successful bypass procedure, resistance was felt while attempting to withdraw the PAV catheter. On fluoroscopy, fixation of the catheter at the heart level was established and perforation by suture was confirmed after injection of a contrast agent. Because of the risk of cardiac wall rupture and tamponade, the thorax was reopened. After release of some atrial sutures, the catheter could be withdrawn easily. Transfixion by a suture was confirmed by visual examination.

Conclusion: The more frequent use of a PAV catheter in minimally invasive cardiac surgery with the port-access technique should remind the anesthesiologist of the higher risk of entrapment by surgical sutures. Surgeons should be aware of the risk of accidentally transfixing this catheter during closure of the atriotomy via the port.

Objectif : La chambre d'accès permet aux chirurgiens de pratiquer des interventions cardiaques au travers de petites ouvertures intercostales ou "chambres». Cette technique exige des anesthésiologistes une nouvelle façon de procéder. Une canule de décharge de l'artère pulmonaire (DAP) et, dans certains cas, une sonde du sinus coronarien (pour l'administration de cardioplégie rétrograde) est mise en place à l'aide de la fluoroscopie et de l'échographie transœsophagienne. Ces cathéters ont un diamètre plus large que le cathéter de I'AP le plus couramment utilisé et ils présentent des caractéristiques distinctes. Nous décrivons un cas où la canule de décharge de l'artère pulmonaire a été piégée dans une suture pendant une intervention avec chambre d'accès.

Éléments cliniques : Un homme de 35 ans souffrant d'insuffisance mitrale sévère devait subir une réparation valvulaire. Après une opération de dérivation réussie, une résistance a été perçue pendant la tentative de retrait de la canule de DAP. La fluoroscopie a montré la fixation de la canule au niveau du coeur et confirmé la perforation près de la suture après l'injection d'un agent de contraste. Étant donné le risque de rupture et de tamponnade de la paroi cardiaque, le thorax a été rouvert. Après avoir libéré quelques points de suture auriculaire, on a pu retirer facilement la canule. La transfixion près de la suture a été confirmée par l'examen visuel.

Conclusion : L'usage plus fréquent de la canule de DAP lors d'intervention à effraction minimale, selon la technique de la chambre d'accès, devrai rappeler à l'anesthésiologiste le risque plus élevé de voir une canule prise dans les sutures chirurgicales. Pour leur part, les chirurgiens doivent connaitre le risque de transfixion accidentelle de cette canule pendant la fermeture de l'atriotomie en passant par la chambre d'accès.

From the Department of Anesthesia and Intensive Care, Clinic of Cardiac Anesthesia, Onze Lieve Vrouw Clinic, Aalst, Belgium. Address correspondence to: S. Deneu MD, Department of Anesthesiology \& Intensive Care, Jules Bordet Institute, l, rue Héger Bordet, 1000 Brussels, Belgium.

Accepted for publication July 11, 1999 


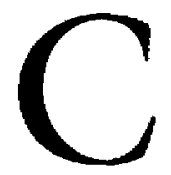

ENTRAL venous and pulmonary artery catheterizations are not harmless procedures. A variety of complications has been reported, ${ }^{\mathrm{I}-2}$ including knotting and accidental entrapment by sutures. The introduction of new types of catheters (Heartport Inc, $B$ Redwood City $\mathrm{CA}$ ) placed by the anesthesiologist during techniques of minimally invasive cardiac surgery, leads to reconsideration of their potential complications. We report a case where a pulmonary artery venting (PAV) catheter was entrapped by surgical sutures.

\section{Case Report}

A 35-yr-old man was scheduled for mitral valve repair. He had a six month history of palpitations and dyspnea on exertion, associated with mitral valve insufficiency (grade $3 / 4$ ). His medical history revealed heavy smoking. He had never had surgery. On clinical examination, an apical mid-systolic murmur $3 / 6$ was heard and no sign of heart failure were present. Cardiac catheterization showed normal coronary arteries and pulmonary artery pressures. Echocardiography revealed normal LV function without aortic valve discase.

After an uneventful induction of anesthesia with sufentanil and propofol, a coronary sinus catheter (EndoCoronary ${ }^{\mathrm{TM}}$ sinus catheter, Heartport $\left.{ }^{(}\right)$) and a PAV (EndoVent ${ }^{\mathrm{TM}}$ pulmonary catheter, Heartport ${ }^{\mathrm{B}}$ ) were inserted easily via the right internal jugular vein in, respectively, the coronary sinus and the main pulmonary artery. The surgeon performed a $15 \mathrm{~cm}$ incision for right thoracotomy. Following heparinization, femoral arterial and yenous cannulae were inserted and their positions controlled by TEE. Cardiopulmonary bypass (CPB) was started and cardiac arrest induced via the occlusive aortic catheter (Endoaortic Clamp Heartport ${ }^{\mathrm{TM}}$ ) and cold cardioplegia. Under video-assistance the surgeon performed an annuloplasty with ring implantation on the mitral valve. After uncomplicated CPB weaning and pericardial closure, the right lung was manually re-inflated and two-lung ventilation restored. The right thoracotomy was then closed. Doppler examination revealed no paravalvular leak or valve dysfunction. Hemodynamic parameters remained stable. While trying to remove the PAV catheter, resistance was felt. Fluoroscopy was used to exclude knotting of the PAV catheter. Removal was attempted under fluoroscopy, but the cardiac silhouette moved with traction. Contrast agent was then injected which showed a leakage with spread in the atrial cavity and still a normal passage to the distal lumen (Figure 1). Suture-related entrapment was diagnosed. Because of the possibility of vessel wall rupture, the right chest was reopened. Pericardial stitches were first removed but this did not remove the resistance. The right atrium was

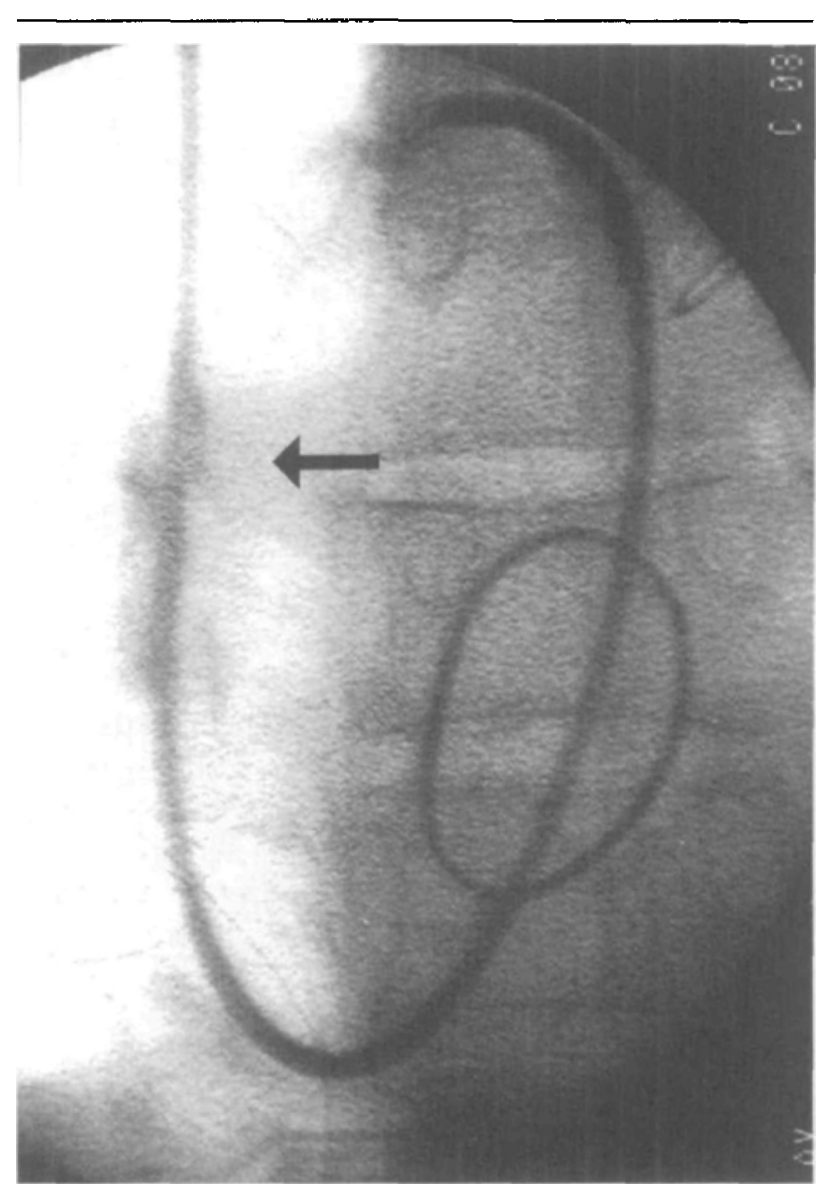

FIGURE 1 Fluoroscopic image of the PAV catheter demonstrating leakage at the site of the defect after contrast injection (arrow).

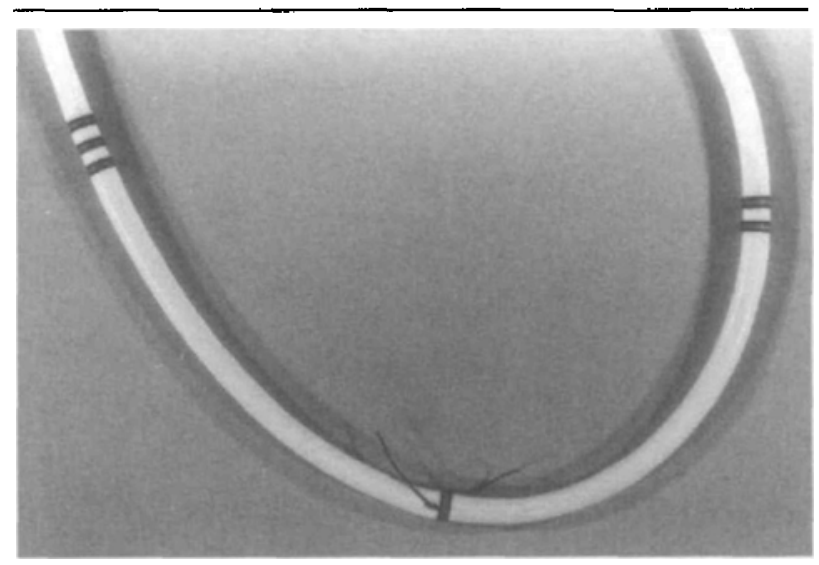

FIGURE 2 Photograph of the PAV catherer after operative removal. 
reopened and the PAV catheter could then be easily withdrawn. Examination revealed that the catheter had been transfixed by a stitch (Figure 2) while suturing the left atrium.

\section{Discussion}

Difficulties in removal of PA catheters have been reported previously, knotting of the catheter being one of the most frequently encountered mechanisms. ${ }^{2-3}$ Less frequently, sutures have ensnared and entrapped PA catheters during open heart surgery, at the atrial or ventricular level. Extraction of fixed catheters has been performed percutaneously or surgically. ${ }^{4}$ Perforation by suture in the right atrial wall involves the risk of tamponade during attempts at catheter withdrawal. Because the catheter can remain functional, this complication is often diagnosed late.

Port-access cardiac surgery is a new approach which provides the benefits of minimally invasive surgery without sacrificing the advantages of cardiopulmonary bypass and myocardial preservation. ${ }^{5}$ Thoracic ports, in conjunction with a specially designed set of endovascular catheters, help the surgeon to perform coronary revascularisation, mitral valve surgery, ASD closure, tricuspid valve surgery or myxoma resection in a space limited working area. ${ }^{5-6}$ Although it may be less traumatic than standard open-chest heart surgery, port-access surgery is still a major cardiac procedure with the potential for some of the same risks and complications as conventional open-chest heart surgery, including damage to major blood vessels or heart structures, chest wound pain or infection, bleeding from the wound, irregular heartbeat, stroke and death. Only two small clinical series have demonstrated the feasibility of the technique and report data. ${ }^{7-8}$ There are no controlled or blinded studies. Stitch entrapment of a PAV catheter during port-access cardiac surgery has not been reported.

The coronary sinus and PAV catheters have a diameter of 8.3 and $9 \mathrm{Fr}$, respectively. Comparatively, the conventional PA catheter is $7.5 \mathrm{Fr}$. The larger diameter increases the risk of suturing or perforation. Moreover, a catheter warmed inside the body softens and does not offer unusual resistance to the passage of a needle. It is true for the Swan-Ganz multilumen catheter and consequently even more for the more flexible PAV catheter, that has only one lumen.

Finally, the thoracoscopic instruments specifically designed for minimally invasive surgery do not allow direct contact with anatomical structures nor allow the perforation of a catheter to be perceptible. Passage of a suture through a PA catheter does not consistently cause severe malfunction such as balloon failure or dampened PA trace. In this case, the port-access vent catheter was perforated after CPB. Earlier piercing would probably not have altered function, which makes early presumptive diagnosis of perforation unlikely.

Successful extraction of entrapped PA catheters by percutaneous methods has been reported..$^{9-10} \mathrm{~A}$ scalpel blade attached to a dilator or repeated traction with dilatating catheters passed over the PA catheter have permitted non surgical relief. We estimated the risk of such procedures was too high for the portaccess PAV catheters.

We have now taken steps to decrease the possibility of catheter entrapment by sutures during port-access cardiac operations. As soon as pulmonary venting is stopped and the heart refilled, and before pericardial closure, the two catheters are mobilized and removed early, leaving only the two introducer sheaths in place.

\section{Conclusion}

We report a case of entrapment of a PAV catheter during port-access cardiac surgery, a new type of minimally invasive surgical cardiac procedure. Though this type of complication has been described after PA catheterization during conventional cardiac surgery, both the new catheters used and the limited access to the surgical field render the complication more likely to happen. To avoid this, we advise the early withdrawal of the catheters before complete surgical closure.

\section{References}

1 Zarshenas $Z$, Sparschu $R A$. Catheter placement and misplacement. Crit Care Clin 1994; 10: 417-36.

2 Kelso LA. Complications associated with pulmonary artery catheterization. New Horiz 1997; 5: 259-63.

3 Purdue GF, Hunt JL. Placement and complications of monitoring catheters. Surg Clin North Am 1991; 71: 723-31.

4 Vucins EJ, Rusch JR, Grum CM. Vent stitch entrapment of Swan-Ganz catheters during cardiac surgery. Anesth Analg 1984; 63: 772-4.

5 Siegel LC, St Goar FG, Stepens JH, et al. Monitoring considerations for port-access cardiac surgery. Circulation 1997; 96: 562-8.

6 Siegel LC, Peters WS, St Goar FG, et al. Anesthetic considerations for port-access cardiac surgery (Abstract). Anesth Analg 1996; 82: SCA79.

7 Reichenspurner $H$, Gulielmos $V$, Wunderlich J, et al. Port-access coronary artery bypass grafting with the use of cardiopulmonary bypass and cardioplegia arrest. Ann Thorac Surg 1998; 65: 413-9.

8 Ribakope GH, Miller JS, Anderson RV, et al. Minimally invasive port-access coronary artery bypass grafting with early angiographic follow-up: initial clinical experience. J Thorac Cardiovasc Surg 1998; 115: 1101-10. 
9 Lazzam C, Sanborn TA, Christian F Jr. Venricular entrapment of a Swan-Ganz catheter: a technique for nonsurgical removal. J Am Coll Cardiol 1989; 13 :

1422-4.

10 Wholey $M$, Zikria $E A$, Boyle $B$. Inadvertant atrial fixation of a Swan-Ganz catheter by suture and a method for its percutaneous removal. Cardiovasc Intervent Radiol 1987; 10: 171-4. 